Louisiana State University

LSU Digital Commons

$4-21-2017$

\title{
A Near-Infrared, Wavelength-Shiftable, Turn-on Fluorescent Probe for the Detection and Imaging of Cancer Tumor Cells
}

\author{
Zhenhua Shen \\ Louisiana State University \\ Bijeta Prasai \\ Louisiana State University \\ Yuko Nakamura \\ National Cancer Institute (NCl) \\ Hisataka Kobayashi \\ National Cancer Institute (NCI) \\ Milcah S. Jackson \\ Louisiana State University
}

See next page for additional authors

Follow this and additional works at: https://digitalcommons.Isu.edu/chemistry_pubs

\section{Recommended Citation}

Shen, Z., Prasai, B., Nakamura, Y., Kobayashi, H., Jackson, M., \& McCarley, R. (2017). A Near-Infrared, Wavelength-Shiftable, Turn-on Fluorescent Probe for the Detection and Imaging of Cancer Tumor Cells. ACS Chemical Biology, 12 (4), 1121-1132. https://doi.org/10.1021/acschembio.6b01094

This Article is brought to you for free and open access by the Department of Chemistry at LSU Digital Commons. It has been accepted for inclusion in Faculty Publications by an authorized administrator of LSU Digital Commons.

For more information, please contact ir@lsu.edu. 


\section{Authors}

Zhenhua Shen, Bijeta Prasai, Yuko Nakamura, Hisataka Kobayashi, Milcah S. Jackson, and Robin L. McCarley 


\section{Abstract}

Fast, selective, and noninvasive reporting of intracellular cancer-associated events and species will lead to a better understanding of tumorigenesis at the molecular level and development of precision medicine approaches in oncology. Overexpressed reductase presence in solid tumor cells is key to cancer progression and protection of those diseased cells from the oxidative effects of therapeutics meant to kill them. Human NAD(P)H:quinone oxidoreductase isozyme I (hNQO1), a cytoprotective 2-electron-specific reductase found at unusually high activity levels in cancer cells of multiple origins, has attracted significant attention due to its major role in metastatic pathways and its link to low survival rates in patients, as well as its ability to effectively activate quinonebased, anticancer drugs. Accurate assessment of hNQO1 activities in living tumor models and ready differentiation of metastases from healthy tissue by fluorescent light-based protocols requires creation of hNQO1-responsive, near-infrared probes that offer deep tissue penetration and low background fluorescence. Herein, we disclose a quinone-trigger-based, near-infrared probe whose fluorescence is effectively turned on several hundred-fold through highly selective reduction of the quinone trigger group by hNQO1, with unprecedented, catalytically efficient formation of a fluorescent reporter. hNQO1 activity-specific production of a fluorescence signal in two-dimensional cultures of respiring human cancer cells that harbor the reductase enzyme allows for their quick (30 min) high-integrity recognition. The characteristics of the near-infrared probe make possible the imaging of clinically relevant three-dimensional colorectal tumor models possessing spatially heterogeneous hNQO1 activities and provide for fluorescence-assisted identification of submillimeter dimension metastases in a preclinical mouse model of human ovarian serous adenocarcinoma.

\footnotetext{
*Corresponding Author tunnel@1su.edu.

Author Contributions

All authors have given approval to the final version of the manuscript.

Supporting Information

The Supporting Information is available free of charge on the ACS Publications website at DOI: 10.1021/acschem-bio.6b01094. Additional figures; experimental conditions; spectral properties of Q3STCy, TCy, and IBuTCy; colocalization images; detailed synthetic procedures; and characterization $\left({ }^{1} \mathrm{H}\right.$ and ${ }^{13} \mathrm{C}$ NMR spectra and HR-MS spectra) of compounds (PDF)

Notes

The authors declare no competing financial interest.
} 


\section{Graphical Abstract}

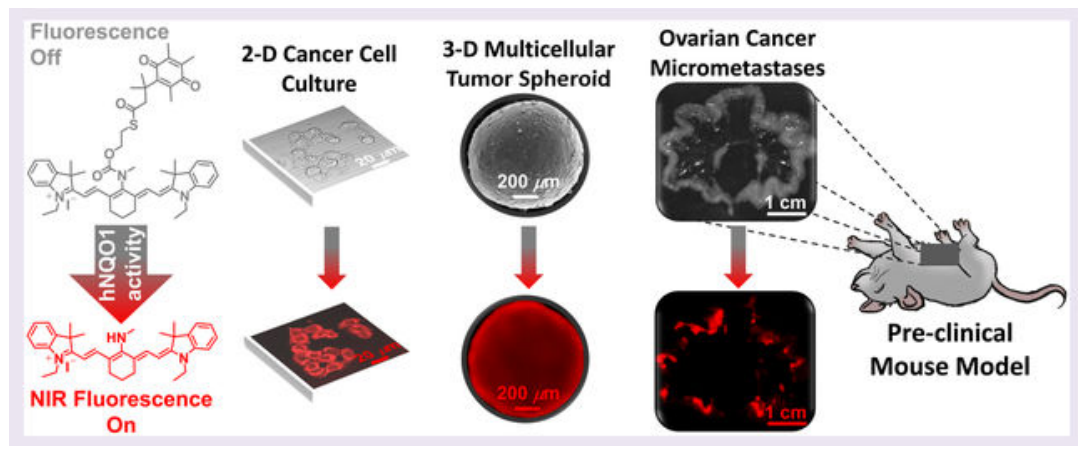

Although initially thought to be protective of only healthy tissue cells by their ability to combat cancer-initiating reactive oxygen species (ROS), ${ }^{1}$ certain reductases that are upregulated in various tumor-derived cell lines and especially those tumor cells experiencing hypoxic conditions are pivotal to their survival during prolonged oxidative attack, ${ }^{2}$ the latter being the major cell-killing pathway provided by chemo- and radiotherapies. ${ }^{3}$ Importantly, metastasis from primary solid tumors to other sites can occur via a redox-based escape mechanism that relies upon adaptive cancer cells possessing significantly elevated levels of ROS-combating reductases, ${ }^{2}$ and the ability to change phenotype in order to exist as isolated, individual cells. ${ }^{4}$ As a result, the presence of said reductases at upregulated values within cancer cells, such as human $\mathrm{NAD}(\mathrm{P}) \mathrm{H}$ :quinone oxidoreductase isozyme I (hNQO1) that has been found at elevated levels in more than $50 \%$ of the NCI-60 tumor cell line database, ${ }^{5,6}$ has been identified as key in the development of a new generation of anticancer drugs (e.g., mitomycin $\mathrm{C},{ }^{7} \beta$-lapachone, ${ }^{8,9}$ deoxynyboquinones ${ }^{10}$ ) whose success is derived from their selective reductase activation.

Interestingly, only recently have the tools been investigated that are necessary to leverage upregulated, cytoprotective reductase presence in human cancer cells, so as to allow the latter's identification, imaging, and study. ${ }^{1-14}$ This nascent field poses a great challenge for the measurement and imaging science communities with regard to creation of approaches that selectively and sensitively report on overexpressed reductase activity in living cancer tissues. Such yet-to-be-implemented approaches will have a potentially large impact on knowledge regarding tumorigenesis and metastasis, as well as in precision medicine-based diagnoses and treatments of cancer. Turn-on, enzyme substrate probe-based fluorescence ${ }^{15-18}$

Turn-on, enzyme substrate probe-based fluorescence ${ }^{15-18}$ holds much promise as a transduction path for the determination of cytoprotective reductase presence and activity within tissue cells, with the caveat that its successful application requires the existence of fluorescently silent, reductase-sensitive probes that can efficiently penetrate into cells and then be selectively and rapidly converted to a highly fluorescent reporter by the enzyme. The resulting emitted light from an appropriately designed reporter has the potential to describe the temporal and spatial dependence of reductase activity within a single cell or in two- and three-dimensional assemblies of cells. In addition, it may be possible that upregulated 
enzyme activities in abnormal cells will yield a fluorescence signal that is sufficient to allow for differentiation of diseased and healthy tissue with cellular resolution. To date, a select group of endogenous reductases has been targeted in the development of turn-on fluorescent probes that can be used to image and detect human cancer cells overexpressing a given reductase, including nitroreductases, ${ }^{19-23}$ human aldo-ketoreductase,,${ }^{13}$ thioredoxin reductase, ${ }^{11}$ and hNQO1. ${ }^{14,24-26}$ However, for end-goal applications that target the study of microenvironmental effects ${ }^{27}$ in three-dimensional multicellular tumor mimics ${ }^{28}$ and their use in drug evaluation studies, ${ }^{29,30}$ and realtime determination of borders between cancerous and normal tissues during surgery, ${ }^{31-34}$ not only must the optical properties of a probe be distinctly different from those of the reductase-generated fluorescent reporter so as to yield a high target-to-background signal ratio ${ }^{14,35}$ but the energies for reporter excitation and emission should lead to less tissue absorption and scattering events- a scenario achieved at wavelengths above $600 \mathrm{~nm} \cdot{ }^{32,33}$ At the time of this writing, there are no reports of reductase-sensitive probes that meet these criteria.

hNQO1, aka DT-diaphorase, is a cytosolic, two-electron-specific reductase whose expression is regulated by the Kelch-like, ECH-associated protein 1 (Keap1)/nuclear factor E2-related factor 2 (Nrf2)/antioxidant response element (ARE) pathway, similar to other cytoprotective reductases. ${ }^{2,3,5}$ Under normal cellular conditions, the Keap1 protein binds to the Nrf2 transcription factor to promote its demise through ubiquitination followed by proteasomal degradation. However, in response to increased oxidative stress, Keap1 loses its capability to target and degrade the Nrf2 transcription factor, due to oxidation of cysteine sites in Keap1. As a result, Nrf2 is transported into the nucleus where it accumulates and binds to an ARE sequence, thereby triggering hNQO1 expression. ${ }^{36-38}$ In normal cells, hNQO1 levels are typically low, but the enzyme is known to be highly upregulated in many types of cancer cells and solid tumors, 6,39 and in particular, those cancers that are or have become resistant to chemo- and radiotherapies. ${ }^{40-42}$ Importantly, hNQO1 overexpression has been directly linked to tumorigenesis and cancer stem cell phenotype, ${ }^{4,43}$ as well as poor patient survival. ${ }^{44-48}$ Therefore, development of hNQO1-activatable profluorogenic probes that target the elevated hNQO1 found in solid tumors is useful for understanding enzymatic processes at the molecular level and developing tools to determine borders between diseased and healthy tissue during fluorescence-assisted surgery.

We report here the development and in vitro and in vivo evaluation of a profluorogenic probe, $\mathrm{Q}_{3} \mathrm{STCy}$, whose latent electron-transfer-quenched NIR fluorescence is selectively turned on by hNQO1 reduction of the $\mathrm{Q}_{3}$ trigger group to yield the corresponding fluorescent reporter TCy, Scheme 1. A unique feature of the quinone reductase-triggered, near-infrared (NIR) probe/reporter system is the low background signal that results from the significant difference in probe and reporter excitation and emission energies, an outcome achieved by use of a self-eliminating, electronically altering linker. Importantly, the latter yields an unprecedented probe activation efficiency, paving the way for probe use in realtime imaging applications. To that end, the energies for TCy reporter excitation and emission are such that tissue damage and autofluorescence background signal limitations are not concerns, thereby demonstrating the advantages of the new probe-reporter system versus extant NQO1-responsive probes. ${ }^{14,24-26,49}$ Furthermore, the carefully crafted NIR probe/ reporter system does not suffer from structural alterations or changes in reporter signal 
transduction that result from the presence of biologically active, potentially cross-reactive species in the cellular milieu; such events have impeded progress in the development of activatable NIR probes. Finally, we show that the new NIR probe is capable of detecting hNQO1 activity in two- and three-dimensional cultures of human cells and an in vivo preclinical tumor model, allowing for identification of tiny ovarian cancer tumors.

\section{RESULTS AND DISCUSSION}

\section{Design, Preparation, and Characterization of the $Q_{3} S T C y$ Probe.}

To achieve a successful profluorogenic hNQO1-specific probe of practical application in several disciplines, many design factors need to be carefully considered. hNQO1 is an intracellular enzyme present mainly within the cytosol; its location can provide an advantage for numerous applications, especially those for which retention of hNQO1 generated reporter within target cells offers their ready discrimination from nontarget normal cells or the ability to provide quantitative information on cellular enzyme activity levels. For example, such a scenario is a prerequisite for successful real-time cytoreductive surgical removal of cancerous tissue that requires sustained, time-invariant, target-to-background ratios (TBRs). ${ }^{35}$ Furthermore, this tack will allow for correlation of prodrug efficacy and their hNQO1-based activation in cellular assays. ${ }^{50}$ To that end, cell membrane permeability of the probe and cellular retention of the resulting reporter are essential for the development of hNQO1-activatable probes. In addition, for an effective reporting of cellular hNQO1 activities, the probe will be recognized and activated selectively by hNQO1 without any interference from competing reducing agents (e.g., biothiols and reductases) found in the complex physiological environment. Furthermore, to achieve remarkable TBR values as a result of ready differentiation of the reporter emission signal from the background, the probe and the reporter will have distinct photophysical properties. As such, the reporter will have

photostable emission that occurs at an energy much different than that of absorption ( $\lambda_{\text {abs }}$ vs $\lambda_{\mathrm{em}}$, large Stokes shift), is insensitive to $\mathrm{pH}$ changes, and yields a high brightness $(\varepsilon \times \Phi)$. In contrast, the unactivated probe is to possess a low fluorescence quantum efficiency, significantly different absorption and emission profiles from the reporter, and good environmental stability.

With these criteria in mind, the tricarbocyanine TCy (Scheme 1) was selected as the reporter because of its anticipated NIR absorption/emission wavelengths that possess large Stokes shifts, high quantum efficiency, and photo-stability. ${ }^{51,52}$ Importantly, the methylamine group in its meso position provides a synthetic handle that can be functionalized with an hNQO1 specific trigger $\left(\mathrm{Q}_{3}\right)$. Small changes in the electronic properties of substituents at the meso position can induce large changes in photophysical properties of the TCy reporter due to the nature of its $\pi$-electron density distribution. ${ }^{53,54}$ Introduction of an electron-withdrawing carbamate bond at the meso position is posited to significantly alter the electron density on the backbone of the TCy, thereby generating dramatic changes in the photophysical properties of the TCy reporter. The trimethyl locked quinone propionic acid $\mathrm{Q}_{3}$ motif has been successfully demonstrated as a highly selective hNQO1 substrate, capable of being catalytically reduced to its hydroquinone with NADH cofactor; this trigger group has been targeted in the design of bioreductive prodrugs, ${ }^{55-58}$ nanomaterials, ${ }^{59,60}$ drug delivery 
systems, ${ }^{61}$ and imaging probes. ${ }^{14,24-26,49}$ Furthermore, in the $\mathrm{Q}_{3}$ STCy probe, the $\mathrm{Q}_{3}$ group will not only act as an hNQO1-specific trigger, but its electron-deficient nature is anticipated to allow it to be an effective photoinduced electron-transfer (PeT) quencher of the fluorescence of the covalently linked TCy reporter. Finally, the self-eliminating 2mercaptoethanol linker between the $\mathrm{Q}_{3}$ trigger and the bulky TCy reporter is expected to result in enhanced enzyme activation of $\mathrm{Q}_{3} \mathrm{STCy} .{ }^{62}$

The synthetic route for $\mathrm{Q}_{3} \mathrm{STCy}$ is outlined in Scheme $\mathrm{S} 1$. To help provide a rationale regarding the unreported spectroscopic properties of $\mathrm{Q}_{3} \mathrm{STCy}$, as well as investigate the influence of $\mathrm{Q}_{3} \mathrm{PA}$ on the photophysical properties of $\mathrm{Q}_{3} \mathrm{STCy}$, a structural analogue of $\mathrm{Q}_{3} \mathrm{STCy}$, namely ${ }_{\mathrm{B}} \mathrm{BuTCy}$ without the $\mathrm{Q}_{3} \mathrm{PA}$ moiety, was also prepared. All compounds were characterized with ${ }^{1} \mathrm{H}$ NMR, ${ }^{13} \mathrm{C}$ NMR, and ESI-HRMS and gave satisfactory outcomes (Supporting Information).

\section{Photophysical Properties.}

As shown in Figure 1, the spectral behavior of the $\mathrm{Q}_{3} \mathrm{STCy}$ probe and TCy reporter was measured in phosphate-buffered aqueous solution (PBS, $\mathrm{pH}=7.4$ ). In contrast to the $\mathrm{Q}_{3} \mathrm{STCy}$ probe, the TCy reporter has distinct spectroscopic properties that are anticipated to allow for ready differentiation of a reporter signal from that of the probe in complex biological environments. Of particular note is the large difference in maximum energy of absorption for the TCy reporter $\left(\lambda_{\mathrm{abs}}{ }^{\text {reporter }}=606 \mathrm{~nm}\right)$ and the $\mathrm{Q}_{3} \mathrm{STCy}$ probe $\left(\lambda_{\mathrm{abs}}{ }^{\text {probe }}=\right.$ $786 \mathrm{~nm})$, as well as the significant difference in peak emission wavelength $\left(\lambda_{\mathrm{em}}{ }^{\text {reporter }}=755\right.$ $\mathrm{nm}$ vs $\lambda_{\mathrm{em}}{ }^{\text {probe }}=798 \mathrm{~nm}$ ). The dissimilarities in energies of absorption and emission for the TCy reporter and $\mathrm{Q}_{3} \mathrm{STCy}$ probe, caused by introduction of a carbamate bond at the meso position, were examined by investigating the HOMO and LUMO energy levels ${ }^{53}$ of TCy and an analogue of the $\mathrm{Q}_{3} \mathrm{STCy}$ probe that also possesses a carbamate moiety, dubbed $\mathrm{B}$ BuTCy (Scheme $\mathrm{S} 1$ ). The latter is structurally similar to the $\mathrm{Q}_{3} \mathrm{STCy}$ probe, but iBuTCy is more facile to study with computational methods. As determined from semiempirical DFT calculations (B3LYP/6-31G, Figure S4), the energy difference of $1.35 \mathrm{eV}$ in the HOMO and LUMO of $i$ BuTCy is $0.28 \mathrm{eV}$ smaller than the $1.63 \mathrm{eV}$ value for TCy, thereby providing rationale for the observed longer absorption/emission wavelengths of $\imath \mathrm{BuTCy}$, and thus the $\mathrm{Q}_{3} \mathrm{STCy}$ probe, vs those of the reporter. The ability to use, in cellular imaging experiments, an excitation energy that leads to large reporter absorption but almost nonexistent probe absorption is expected to result in a much attenuated background signal from probe fluorescence, in turn leading to high contrast between target cells and nontarget cells. Additionally, the exceedingly large Stokes shift of the TCy reporter $(149 \mathrm{~nm})$ is attributed to formation of an ICT state. ${ }^{51}$ Such a difference in reporter absorption/emission energies will minimize possible reporter self-quenching and thereby provide a high target signal, as well as lead to decreased background associated with scattering of the excitation light.

As expected from the design parameters discussed above, the $\mathrm{Q}_{3} \mathrm{STCy}$ probe is much less fluorescent in aqueous solution than is its corresponding TCy reporter. Quantum yield values $(\Phi)$ of $\mathrm{Q}_{3}$ STCy and TCy were determined from their aqueous solutions (2\% DMSO: 98\% PBS, $\mathrm{pH}=7.4)$ using indocyanine green in water $(\Phi=0.012)^{63}$ and in-house-synthesized $1,1^{\prime}, 3,3,3^{\prime}, 3^{\prime}$-hexamethyl-3,5-propylene-4-(dimethylamino)-2,2' ${ }^{\prime}$-indotricarbocyanine 
perchlorate (HPDITCP) in ethanol $(\Phi=0.161)$ as standards. ${ }^{64} \mathrm{Q}_{3}$ STCy possesses a quantum yield (0.0046) that is 14-fold lower than that of the TCy reporter $(\Phi=0.063)$, Table S1. Through use of the Rehm-Weller equation, in conjunction with voltammetric half-wave potentials and spectroscopic data (Figure S3), a free energy change of $-0.47 \mathrm{eV}$ is computed for the donor-excited photoinduced electron-transfer (d-PeT) quenching of the $\mathrm{Q}_{3} \mathrm{STCy}$ probe, indicating that electron transfer from the excited state of the TCy fluorophore to the electron-deficient quinone moiety is a thermodynamically feasible process. Thus, $\mathrm{Q}_{3}$ is an effective quenching group capable of substantially decreasing the fluorescence quantum efficiency of $\mathrm{Q}_{3} \mathrm{STCy}$. Furthermore, when irradiated near the maximum absorption of the TCy reporter at $600 \mathrm{~nm}-186 \mathrm{~nm}$ less energetic than the absorption peak of the $\mathrm{Q}_{3} \mathrm{STCy}$ probe-the reporter offered a 240 -fold higher emission intensity at $765 \mathrm{~nm}$ compared to $\mathrm{Q}_{3} \mathrm{STCy}$, which is rationalized by the $\sim 10 \times$ higher molar absorptivity of the TCy reporter. In sum, the $\mathrm{Q}_{3} \mathrm{STCy}$ probe/TCy reporter system possesses the required spectral characteristics to make it a strong candidate as a turn-on sensor of hNQO1 activity.

\section{Fluorescence Turn On by hNQO1}

We next examined the efficacy of $\mathrm{Q}_{3} \mathrm{STCy}$ activation by hNQO1 under physiological conditions $\left(37^{\circ} \mathrm{C}\right.$ in $0.1 \mathrm{M}, \mathrm{pH}$ 7.4 PBS). The absorption and emission spectra of $\mathrm{Q}_{3} \mathrm{STCy}$ solutions were recorded over time upon introduction of $688 \mathrm{U} \mathrm{mL}^{-1}$ of hNQO1 with added $100 \mu \mathrm{M}$ NADH cofactor. A total of $1 \mathrm{U}$ of hNQO1 will reduce $1 \mathrm{nmol}$ of cytocytochrome $\mathrm{c}$ $\mathrm{min}^{-1}$ in the presence of menadione substrate at $37{ }^{\circ} \mathrm{C} ;{ }^{24}$ the value of $688 \mathrm{U} \mathrm{mL}^{-1}$ is approximately that found for hNQO1 in HT-29 colorectal cancer cells $\left(761 \pm 18 \mathrm{U} \mathrm{mL}^{-1}\right.$, assuming an average cell volume of $1 \mathrm{pL})^{65}$ using dichlorophenolindophenol as the redox mediator, ${ }^{66}$ vide infra. As shown in Figure $2 \mathrm{~A}, \mathrm{hNQO1}$ presence leads to a rapid decrease in the intensity of the absorption band maximum of $\mathrm{Q}_{3} \mathrm{STCy}$ at $785 \mathrm{~nm}(50 \%$ decrease in 3 $\mathrm{min}, 90 \%$ decrease in $10 \mathrm{~min}$ ), while the intensity of a new band centered at $606 \mathrm{~nm}$, presumed to be that of the TCy reporter, increases concomitantly (50\% increase in $6 \mathrm{~min}$, $90 \%$ increase in $15 \mathrm{~min}$ ); there was an obvious change in solution color from green to blue. Furthermore, the fluorescence emission exhibited an immediate increase at $798 \mathrm{~nm}$, followed by a larger change in intensity at the peak value of the TCy reporter $(755 \mathrm{~nm})$ that led to a 193-fold increase in fluorescence within $20 \mathrm{~min}$, Figure 2B. These spectral changes are assigned to initial formation of a fluorescent intermediate of $\mathrm{Q}_{3} \mathrm{STCy}$ possessing an intact carbamate bond, referred to as STCy, which has spectral properties similar to those of iBuTCy; Scheme 1. Thus, we associate hNQO1 generation of STCy with the initial fluorescence increase at $798 \mathrm{~nm}$. Subsequent intensity increases at the emission maximum of the TCy $(755 \mathrm{~nm})$ are attributed to its formation upon intramolecular cyclizative cleavage of the five-membered 1,3-oxathiolan-2-one (aka thiolanone) in Scheme 1. Mass spectrometry data support these conclusions, vide infra.

To investigate that the hNQO1-induced fluorescence turn on was indeed caused by the release of TCy via the proposed mechanism in Scheme 1, solutions of $\mathrm{Q}_{3} \mathrm{STCy}$ treated with $688 \mathrm{U} \mathrm{mL}^{-1}$ of hNQO1 for 20 min under physiological conditions $\left(37^{\circ} \mathrm{C}\right.$ in $\left.\mathrm{pH} 7.4 \mathrm{PBS}\right)$ were analyzed by HPLC coupled to ESI-TOF mass spectrometry (Figure S5). Four of the expected products were successfully separated and identified, having $\mathrm{m} / \mathrm{Z}$ values of 235.1356 $\left[\mathrm{HQ}_{3}-\mathrm{L}+\mathrm{H}\right]^{+}$, error $=11.5 \mathrm{ppm} ; 610.3458[\mathrm{STCy}]^{+}$, error $=1.4 \mathrm{ppm} ; 506.3539[\mathrm{TCy}]^{+}$, 
error $=0.8 \mathrm{ppm}$; and $842.4639\left[\mathrm{Q}_{3} \mathrm{STCy}\right]^{+}$, error $=8.6 \mathrm{ppm}$. No $\mathrm{H}_{2} \mathrm{Q}_{3} \mathrm{STCy}$ was detected, as expected, due to its rapid cyclization to $\mathrm{HQ}_{3}-\mathrm{L}\left(k_{\text {cycle }} \sim 1 \mathrm{~min}\right)$. We assume that the thiolanone coelutes with solvent between 1 and $2 \mathrm{~min}$. These results confirm the initial formation of STCy upon $\mathrm{Q}_{3}$ STCy treatment by hNQO1, with subsequent TCy release. However, due to differences in ionization efficiencies, we are unable to state how much of the individual species exist with respect to each other after the $20 \mathrm{~min}$ incubation period.

To obtain quantitative information on hNQO1 efficacy in activating $\mathrm{Q}_{3} \mathrm{STCy}$, the apparent kinetic parameters were determined by monitoring the release of the TCy reporter, as noted by fluorescence emission at $\lambda_{\mathrm{em}}=755 \mathrm{~nm}\left(\lambda_{\mathrm{ex}}=605 \mathrm{~nm}\right)$, using various $\mathrm{Q}_{3}$ STCy probe/ substrate concentrations $(0.5-5 \mu \mathrm{M})$, Figure $3 \mathrm{~A}$. The TCy fluorescence intensity was converted to concentration by using a linear calibration curve. Upon fitting the TCy production rate to the Michaelis-Menten equation, an apparent Michaelis constant $K_{\mathrm{m}}=1.1$ $\pm 0.5 \mu \mathrm{M}$ (standard deviation; $n=3$ ) and maximum velocity $\mathrm{V}_{\max }=0.31 \pm 0.05 \mu \mathrm{mol} \mathrm{min}{ }^{-1}$ $\mathrm{mg} \mathrm{hNQO1}{ }^{-1}$ were obtained. On the basis of these values, the catalytic constant or turnover number $k_{\text {cat }}=0.162 \pm 0.024 \mathrm{~s}^{-1}$ and the catalytic efficiency $k_{\text {cat }} / K_{\mathrm{m}}=1.5 \pm 0.7 \times 10^{5} \mathrm{M}^{-1} \mathrm{~s}$ ${ }^{-1}$ were calculated. As of this writing, the bimolecular rate constant $(\mathrm{kcat} / \mathrm{Km})$ is the highest reported for any probe of hNQO1 activity obtained under physiological conditions ( $\mathrm{pH} 7.4$, $0.1 \mathrm{M}$ PBS). For example, the $k_{\mathrm{cat}} \mathrm{K}_{\mathrm{m}}$ value for other hNQO1 probes ranges from 5 to $35 \times$ $10^{3} \mathrm{M}^{-1} \mathrm{~s}^{-1}$, which is $5-30$ times slower than that afforded by the $\mathrm{Q}_{3} \mathrm{STCy}$ probe. We attribute these favorable probe properties to the presence of the self-eliminating 2mercaptoethanol linker that separates the $\mathrm{Q}_{3}$ enzyme trigger group from the bulky TCy reporter. This scenario allows for ready access of the trigger group to the active site of the enzyme - as we have shown in computational and enzyme kinetics studies, ${ }^{62}$ thereby yielding rapid activation of $\mathrm{Q}_{3} \mathrm{STCy}$ by $\mathrm{hNQO1}$ - and it also leads to a hydrolytically stable probe whose fluorescence is effectively quenched in aqueous media. These characteristics are demonstrated with results from time-drive experiments, Figure 3B, wherein was monitored over time the fluorescence of two $\mathrm{Q}_{3} \mathrm{STCy}$ solutions with or without added hNQO1. In the presence of hNQO1, the fluorescence signal due to TCy formation rapidly increased (50\% of maximum in $11 \mathrm{~min}$ ) and reached a plateau near $30 \mathrm{~min}$. There was no significant change in fluorescence signal in the absence of hNQO1, even after $150 \mathrm{~min}$, the longest time examined.

\section{$Q_{3}$ STCy and TCy Stability and Enzyme Selectivity.}

In order to successfully examine enzyme activity levels during in vitro and in vivo studies, it is paramount that the probe provide a highly selective response to the enzyme of interest and both probe and reporter be stable in the absence of the target enzyme. Biological species, oftentimes present in tissue and cells at concentration levels several hundreds to thousands of times higher than probes and reporters used to interrogate a target, have the potential to yield either a false positive report of target presence that is caused by nonselective activation of the trigger group or a low sensitivity response for a given target that results from deactivation of the target-generated fluorescent reporter. The requisite characteristics for a successfully implementable probe/reporter system can be more challenging to obtain for probes whose reporters provide a fluorescence signal in the far-green and near-infrared energy regions, as the structures of the probe and reporter must be carefully crafted to 
provide LUMO and HOMO energy levels that do not lead to interferent-induced redox reactions or quenching events, such as those caused by NADH or glutathione present at levels typical of the cellular environment. ${ }^{24}$

To rule out possible activation of $\mathrm{Q}_{3} \mathrm{STCy}$ by hydrolysis or any interfering biological reductants (e.g., thiols ${ }^{67}$ and other quinone reductases) potentially present and known to be present in mammalian cells, the fluorescence response of $\mathrm{Q}_{3} \mathrm{STCy}$ solutions exposed to various $\mathrm{pH}$ conditions and select species was evaluated. As expected, there was no apparent impact of solution $\mathrm{pH}$ over the range of 4.5 to 9.5, Figure S6. Importantly, there was no significant change in fluorescence even after $20 \mathrm{~min}$ of incubation of the probe with $1 \mathrm{mM}$ glutathione (GSH), ascorbic acid (AA), L-cysteine (Cys), L-homocysteine (Hcy), or dithiothreitol (DTT), all in the absence of hNQO1 cofactor NADH; the results are shown in Figure 4. On the basis of known reactions of NRH:quinone oxidoreductase 2 (QR2, aka NQO2) and cytochrome P450 reductase (CPR) with certain quinone species, ${ }^{14,24}$ we investigated their potential to activate the $\mathrm{Q}_{3} \mathrm{STCy}$ probe in the presence of their respective cofactors, NRH and NADPH; the individual influence of the latter two cofactors on the probe were also studied. A response roughly $20 \%$ of that for hNQO1-catalyzed NADH activation of the $\mathrm{Q}_{3} \mathrm{STCy}$ probe was found when using an NQO2 activity 275 times the highest reported NQO2 activity level in human cancer cells, the latter being a mere $0.2 \%$ of the hNQO1 activity present in the same tumor-derived cancer cell line. ${ }^{68}$ It is important to note the NQO2 cofactor NRH is not native to cells at concentration levels high enough to allow for NQO2 activation of quinone substrates, and NRH is unstable in cellular and aqueous environments. ${ }^{68} \mathrm{CPR}$, in the presence of NADPH cofactor, produced a fluorescence response approximately $10 \%$ that of the signal for hNQO1-catalyzed activation of the probe, even though the CPR activity used here is roughly that found in lung cancer cell monolayers ${ }^{69}$ and $4 \%$ of the hNQO1 activity in colorectal cancer xenografts. ${ }^{70}$ Furthermore, neither hNQO1 nor NADH was independently capable of inducing release of the reporter. These outcomes are significant in the use of the $\mathrm{Q}_{3} \mathrm{STCy}$ probe to identify hNQO1 activity in cancer cells, as they demonstrate the high selectivity of probe activation by hNQO1.

To examine the stability of the selectively released TCy reporter, we studied the effects of $\mathrm{pH}$ and biological reductants (GSH, AA, Cys, Hcy, DTT) on the fluorescence signal of TCy solutions. As shown in Figure S6, variation of aqueous $\mathrm{pH}$ (4.5-9.5) did not result in any meaningful changes in the fluorescence intensity of the TCy reporter. Moreover, the reporting capability of TCy was not influenced by the presence of these biological reducing species, as demonstrated by the lack of any significant variations $(<10 \%)$ in reporter response in comparison to its incubation in PBS for $2 \mathrm{~h}$, Figure S7. In total, the characteristics of the $\mathrm{Q}_{3} \mathrm{STCy}$ probe and TCy reporter bode well for biological imaging applications.

\section{Fluorescence Imaging of Endogenous hNQO1 in Tumor-derived Cancer Cell Monolayers.}

Reassured by the effective and selective nature of $\mathrm{Q}_{3} \mathrm{STCy}$ in detecting hNQO1 activity in vitro, we used confocal microscopy to investigate the ability of $\mathrm{Q}_{3} \mathrm{STCy}$ to identify and differentiate tumor cells based on the presence of hNQO1 activity. The overexpression of hNQO1 in the colorectal carcinoma cell line HT-29 and the ovarian cancer cell line 
OVCAR-3 has been established. ${ }^{6,71}$ In contrast, the nonsmall cell lung carcinoma (NSCLC) cell line H596, known to have undetectable hNQO1 activity resulting from a point mutation, 72 served as an hNQO1-negative cell line. From hNQO1-specific activity assays using dichlorophenolindophenol (DCPIP) as an enzyme substrate, ${ }^{66}$ we validated the high activity of hNQO1 in 24-h-old HT-29 cells (488 nmol DCPIP min $^{-1} \mathrm{mg}$ protein ${ }^{-1}$ ), the lower hNQO1 activity in OVCAR-3 cells ( $8 \mathrm{nmol}$ DCPIP $\mathrm{min}^{-1} \mathrm{mg}$ protein ${ }^{-1}$ ), and undetectable activity in $\mathrm{H} 596$ cells. We report here for the first time that SHIN3 cells derived from an ovarian serous adenocarcinoma ${ }^{73}$ have overexpressed levels of hNQO1, with the activity value ( $55 \mathrm{nmol}$ DCPIP $\min ^{-1} \mathrm{mg}$ protein ${ }^{-1}$ ) being higher than that in OVCAR-3 cells of an equivalent culture age (1 day). In addition, western blot analysis was used to demonstrate hNQO1 expression in the HT-29, OVCAR-3, and SHIN3 cell lines, Figure S8. Monolayers of all four cancer cell lines were incubated with $5 \mu \mathrm{M} \mathrm{Q} \mathrm{Q}_{3}$ STCy in cell culture medium for 30 min under identical conditions, followed by paraformaldehyde cell fixation. As seen in the confocal microscopy images of Figure 5, fluorescence in the near-infrared region (660-820 $\mathrm{nm}$ ) was found for the hNQO1-positive HT-29, OVCAR-3, and SHIN3 cell lines. These observations indicate that the $\mathrm{Q}_{3} \mathrm{STCy}$ probe is cell membrane permeable, in agreement with its very high log octanol-water partition coefficient of 7.9 at $\mathrm{pH} 7.4,{ }^{74}$ and the probe is readily activated by intracellular hNQO1. In contrast, virtually undetectable fluorescence in this energy range was found in the hNQO1-negative H596 cell line, as expected. When cells are exposed to the hNQO1 inhibitor dicoumarol, their subsequent incubation with the probe leads to significantly diminished fluorescence (Figure S9), further supporting intracellular probe activation by the upregulated hNQO1.

So as to offer a more quantitative approach to distinguishing target cells from nontarget (negative) cells, we calculated the target-to-background ratio (TBR), a significant index for predicting the potency of optical imaging agents in real-time cytoreductive surgery for cell/ tissue differentiation. ${ }^{75}$ In the cases at hand, the TBR is defined as the signal from the hNQO1-positive (HT-29, OVCAR-3, SHIN3) cells in an image compared to that from hNQO1-negative H596 cells. TBR values reported at the 95\% confidence interval are $5.4 \pm$ 0.4 for HT-29 (53 cells)/H596 ( 38 cells), $3.0 \pm 0.2$ for OVCAR-3 ( 55 cells)/H596 (38 cells), and $2.2 \pm 0.2$ for SHIN3 ( 32 cells)/H596 (32 cells). All of the TBR values are sufficiently large to support successful use of the $\mathrm{Q}_{3} \mathrm{STCy}$ probe to identify cancerous regions during fluorescence-guided surgery, ${ }^{75}$ as well as allow for $\mathrm{Q}_{3} \mathrm{STCy}$ probe-based assessment of cellular hNQO1 levels in drug efficacy studies. ${ }^{50}$ Furthermore, it is important to note that the cells were washed two times with $\mathrm{pH}$ 7.3 PBS prior to their being fixed and imaged; that the TBR values remain high after this process points to significant retention of the intracellularly produced $\mathrm{TCy}$ reporter from the $\mathrm{Q}_{3} \mathrm{STCy}$ probe.

To further demonstrate the difference in fluorescence signal observed in the cell images is indeed caused by hNQO1 activity level, the fluorescence turn on of $\mathrm{Q}_{3} \mathrm{STCy}$ was evaluated in an hNQO1 gene-transfected H596 cell line and in the wild-type, hNQO1-negative H596 cell line, Figure S10. The difference in hNQO1 activity in the wild-type versus transfected $\mathrm{H} 596$ cells was proven by measuring the specific activity of hNQO1 from cellular protein extracts using dichlorophenolindophenol (DCPIP) as an hNQO1 substrate; 66 in addition, the expression of hNQO1 in the gene-transfected H596 cell line and its absence in the wild-type, hNQO1-negative H596 cell line were demonstrated with western blot analysis of cell 
lysates, Figure S8. From confocal microscopy images, limited fluorescence was observed in wild-type H596 cells, while an approximately 3 -fold ( $3.1 \pm 0.3$; 95\% confidence interval) larger fluorescence intensity was observed in the transfected H596 cells. These experiments clearly show that intracellular conversion of the $\mathrm{Q}_{3}$ STCy probe to the fluorescent TCy reporter reflects differences in hNQO1 activity, thereby allowing for identification of hNQO1-positive cells.

Colocalization experiments were performed with $\mathrm{Q}_{3} \mathrm{STCy}$ and organelle trackers (mitotracker green and lysotracker green DND-26) to determine the ultimate location of TCy in HT-29 cells resulting from its hNQO1-stimulated release within the cytosol. As shown in Figure S11, the fluorescence derived from the released TCy reporter is colocalized well with that of the lysotracker dye. Using the coloc 2 plugin in ImageJ, the Pearson correlation coefficient for colocalization (PCCC) was determined to be 0.77 , a value indicative of excellent TCy/lysotracker colocalization. ${ }^{76}$ In contrast, poor colocalization of TCy and mitotracker green was evident in fluorescence images (Figure S12), and the PCCC value of 0.28 obtained upon their statistical analysis confirmed this. Importantly, TCy released in the cytosol accumulates in the lysosomes and/or late endosomes, allowing for its enhanced intracellular retention. We posit the high TBR values in hNQO1-positive cells result from this reporter retention effect. Furthermore, these outcomes are significant, as certain tricarbocyanine dyes tend to accumulate in the mitochondria, resulting in deleterious effects. 77,78 Cytotoxicity studies with HT-29 cells using $1-2 \mu \mathrm{M}$ probe in DMSO/PBS buffer for 3$\mathrm{h}$ incubations indicate that cell viability $(93.4 \pm 2.1 \%$ and $88.1 \pm 1.1 \%$, respectively) is not significantly impacted.

\section{hNQ01 Activity-based Fluorescence Imaging of Multicellular Tumor Spheroids (MCTSs).}

The shortcomings associated with cell monolayers and the high cost and limited availability of xenograft models in animals, when applied to screening assays, are major hurdles in the successful development of drugs. This is particularly problematic for materials that target solid tumors, as it is often the case that promising preclinical outcomes derived from cell monolayer-based assays do not translate to the patient in the clinic. ${ }^{79}$ As a result, the use of three-dimensional multicellular tumor spheroids (MCTSs) in drug evaluation studies is seen as a pathway toward improved patient outcomes. ${ }^{29}$ This potential is based on the fact that MCTSs closely resemble avascular tumors, whose interiors possess cells that are either dead or near death (senescent) due to an acidic/hypoxic environment unlike that found for monolayer cultures that respond well to drug candidates. The distinct behavior of promising enzyme-activatable drugs within MCTSs is most likely the result of temporospatial enzyme activities that are dictated by the microenvironment of the MCTSs. ${ }^{27}$ Furthermore, laboratory-cultured MCTSs resemble multicellular aggregates isolated from ascites of ovarian cancer patients whose disease has spread by intraperitoneal dissemination, a progression route also common to colorectal, gastric, and pancreatic cancers. ${ }^{80,81}$ These multicellular aggregates are ticking time bombs that upon initial attachment to the peritoneal lining ${ }^{82}$ are too small to be readily identified by surgeons during cytoreductive surgery, ${ }^{75}$ are isolated from the vasculature necessary for effective transmission of chemotherapeutic drugs designed to kill them, and are suggested to be resistant to such therapeutic agents due to a microenvironment that is mimicked by MCTSs. Thus, it is highly valuable to evaluate the 
ability of enzyme-responsive, fluorescence-based probes to be turned on inside cells of submillimeter-sized MCTSs. Such knowledge has immediate implications for fluorescenceguided surgical approaches and longer term ramifications in studies of the spatial dependence of upregulated target enzymes in three-dimensional cell assay applications.

Exposure of live colorectal cancer MCTSs to $\mathrm{Q}_{3} \mathrm{STCy}$ probe leads to its rapid uptake and subsequent hNQO1 activation to yield the TCy reporter, as noted in wide-field fluorescence microscopy images, Figure 6. We selected MCTSs of advanced culturing age because their microenvironment more closely reflects that of multicellular aggregates and avascular metastases in vivo, ${ }^{30,83}$ with the 23-day-old HT-29 MCTSs used here having a 100- $\mu \mathrm{m}$ thick viable cell layer at the periphery and a highly hypoxic, necrotic core. Although the measured fluorescent signal from the TCy reporter using the Cy5 filter $\left(\lambda_{\mathrm{em}}=662-738 \mathrm{~nm}\right)$ is distinct from that of its precursors, the recorded response with the Cy7 filter $\left(\lambda_{\mathrm{em}}=765-\right.$ $855 \mathrm{~nm}$ ) reflects the summed fluorescence of the $\mathrm{Q}_{3}$ STCy probe and any STCy intermediate possibly present. Prior to probe introduction, there is no significant fluorescence present in either detection channel. However, exposure of the MCTSs to the $\mathrm{Q}_{3} \mathrm{STCy}$ probe leads to almost immediate increases in fluorescence, as noted by both the micrographs and total MCTS fluorescence intensity from said images. Relatively linear time-dependent fluorescent responses are observed for both emission ranges in the entire MCTS region of interest during the 3-h experimental period, the longest time used. We attribute the heterogeneity of TCy reporter fluorescence (brighter near periphery) to an hNQO1 activity in the $\sim 100-\mu \mathrm{m}$ thick viable cell layer that is much higher than in the necrotic core of the 23-day-old spheroids; MCTSs cultured for 15 days or less do not exhibit such a core of dead and dying cells. ${ }^{84}$ In sum, the outcomes from the MCTS studies indicate that the activatable $\mathrm{Q}_{3} \mathrm{STCy}$ probe quickly penetrates into the three-dimensional cancer tumor mimics and gains entry to their component cells, where it reports on cytosolic hNQO1 activity.

\section{Identification of Peritoneal Ovarian Cancer Micrometastases in an in Vivo Mouse Xenograft Model.}

Having demonstrated successful detection of upregulated hNQO1 activity within various cancer cell lines cultured in two and three dimensions, we wished to explore the potential of the $\mathrm{Q}_{3} \mathrm{STCy}$ probe for in vivo identification of tiny cancer foci in an animal model. The ability to visualize and surgically remove $<1$-mm-diameter metastatic lesions that result from intraperitoneal dissemination will have important ramifications in the treatment of colorectal, gastric, pancreatic, and ovarian cancers. For example, it has been shown that the median overall survival of patients is twice as great (64 months) if the surgeon is able to remove ovarian cancer tumors less than $1 \mathrm{~mm}$ in dimension versus patients with residual diseased tissue larger than $1 \mathrm{~mm} .{ }^{85}$

Successful resection of such small cancers is predicated on their identification/detection, a feat impeded by poor differentiation of diseased and healthy tissues during traditional white light examination. ${ }^{31,75}$ Fluorescence-guided surgery ${ }^{31-33}$ that is based on topical application of activatable probes holds much promise for discrimination of tissues, ${ }^{86-88}$ because such turn-on probes outshine their always-on fluorescent counterparts as a result of increased target-to-background signal ratio and exceedingly rapid nature of the visualization events, 
oftentimes on the time scale of minutes. ${ }^{75}$ Importantly, cell-permeable probes that are activated by cancer-associated intracellular enzyme targets to yield cell-retained fluorescent reporters hold the possibility of providing diseased/healthy tissue discrimination with near cellular resolution. To date, only two intracellular enzyme-probe systems have been used to detect human cancers in preclinical studies, namely, one based on $\beta$-galactosidase ${ }^{89}$ that is overexpressed in ovarian cancers and another targeting hexosaminidase, which is upregulated in colorectal cancer cells $;{ }^{90}$ both enzymes reside in the lysosomes.

Exposure of peritoneal xenograft tumors in living mice to dilute solutions of $\mathrm{Q}_{3} \mathrm{STCy}$ probe subsequently affords ready detection of ovarian cancer tumors as small as $\sim 0.5 \mathrm{~mm}$ in dimension, Figure 7 . Although imperceptible by white light, the tiny ovarian cancer tumors are clearly visible in spectral images of the excised mesentery that correspond to the red fluorescent protein (RFP)-transfected SHIN3 cells and their interaction with the $\mathrm{Q}_{3} \mathrm{STCy}$ probe. We selected the low hNQO1-expressing SHIN3 cells in the xenograft studies so as to demonstrate the capabilities of the $\mathrm{Q}_{3} \mathrm{STCy}$ probe. Under the same imaging conditions as xenograft animals, there were no detectable signals in control animals that did not possess tumors (Figure 7, control). Importantly, spectral acquisition and unmixing allows for examination of the integrity of cancer foci identification by the $\mathrm{Q}_{3} \mathrm{STCy}$ probe, which is achieved by a side-by-side comparison of the resulting " $\mathrm{Q}_{3}$ STCy image" and the "RFP image" produced by the genetically encoded fluorescent protein in the SHIN3-DsRed ovarian cancer cells. ${ }^{91}$ As seen in Figure 7, the fluorescence signal generated by $\mathrm{Q}_{3} \mathrm{STCy}$ incubation in the peritoneum of mice possessing SHIN3-DsRed tumors is mostly coincident with RFP-positive foci, thereby demonstrating the ability of the NIR probe to identify the presence of the hNQO1-overexpressing SHIN3 cells. However, in the $\mathrm{Q}_{3} \mathrm{STCy}$ image, the fluorescence signal is sometimes noted in areas of the small bowel adjacent to the RFPlabeled tumor nodules, suggesting possible nonspecific activation of the probe within healthy, neighboring cells in these regions. We posit this observation is actually due to probe activation in healthy cells having higher-than-normal hNQO1 activity that results from their being stimulated by products released from their cancer cell neighbors. Such a scenario is supported by reports of higher-than-normal hNQO1 expression within some healthy tissues in immediate proximity to cancerous tissue; ${ }^{92}$ this was attributed to induced hNQO1 activity in normal tissue cells by membrane-permeable materials released from tumor cells, ${ }^{93,94}$ with said inducing agents potentially being the cause of increased hNQO1 activity in cancer cells cultured at high cell density. ${ }^{95,96}$ This observation with hNQO1 may eventually lead to limitations in the resolution of surgical resections that rely upon hNQO1-based probes, similar to what is possible with extracellularly activated probes whose reporters may enter cancerous and nearby healthy cells.

It is of particular note that short exposure times and dilute concentrations of $\mathrm{Q}_{3} \mathrm{STCy}$ probe in the peritoneum result in effective identification of peritoneally disseminated ovarian cancer by fluorescence-activated imaging, in a spectral range that allows for deep penetration of light into tissue. These outcomes are quite valuable, as the construction and successful use of NIR probes and reporters for in vivo biomedical imaging applications is exceedingly challenging. Development of enzyme-activatable, cell-penetrable NIR probes is complicated by the multitude of structure and size limitations imposed on the probe, oftentimes making so poor the efficiency of enzymatic activation that topical application of 
the probe is no longer feasible. As a result, the use of intravenously delivered always-on fluorescent molecules that target cell surface uptake receptors has been extensively investigated, but they oftentimes yield high background fluorescence signals that decrease the TBR due to their being taken up by cancer tissue in nonspecific ${ }^{92}$ or inefficient ${ }^{97}$ ways. Although synthetic elaboration of the structure of tissue-targeting NIR molecules can yield a lower background signal, ${ }^{98}$ the time needed for them to reach the target site is large. Also, due to their intravenous delivery at relatively high concentrations, they face the prospect of regulatory agency approval, similar to that for new drug molecules. ${ }^{31}$ Furthermore, systemically introduced reporters cannot access remote diseased tissues, such as multicellular tumor spheroids associated with ovarian cancer metastasis and reoccurrence. ${ }^{80}$ Thus, our achievements with the $\mathrm{Q}_{3}$ STCy NIR probe demonstrate the strength of locally applied, activatable molecules for fluorescence-based identification of diseased tissues, particularly those overexpressing reductases that are key to disease progression.

\section{Conclusions}

We have developed a novel NIR probe that provides high-fidelity detection and visualization of endogenous intracellular $\mathrm{NAD}(\mathrm{P}) \mathrm{H}$ quinone reductase activity in two- and threedimensional cancer cell cultures and an in vivo preclinical model of peritoneally disseminated ovarian cancer. hNQO1-specific reductive activation of the carefully crafted, electron-transfer-quenched probe leads to autonomous release of its corresponding tricarbocyanine reporter, which possesses an NIR fluorescence emission that is energetically distinct and several orders of magnitude more intense than that of the inactive probe. The characteristic target-to-background signal provided by the probe/reporter system allows for facile microscopic detection and differentiation of human cancer cells possessing varied hNQO1 activity levels, including cells experiencing different microenvironments as a result of their location in multicellular tumor mimics. Local application of dilute solutions of the probe in mouse xenograft models leads to identification of human ovarian cancer tumors as small as $0.5 \mathrm{~mm}$ in dimension. In total, the quinone reductase-activatable probe holds much promise in the evaluation of drug action and efficacy in clinically relevant tumor models and preclinical animal investigations that address the specificity and sensitivity of microtumor detection, the latter a topic of current investigation in our laboratories.

\section{Supplementary Material}

Refer to Web version on PubMed Central for supplementary material.

\section{ACKNOWLEDGMENTS}

We thank D. Boothman and M. Silvers at the University of Texas Southwest Medical Center for the gift of the H596 (+) cells and Ms. R. McCarley for the table of contents artwork. We extend our appreciation to the LSU AgCenter Biotechnology Laboratory Animal Cell Culture Facility for use of infrastructure and instrumentation. B.P. thanks the Louisiana Economic Development Assistantship Program at LSU.

Funding

This material is based upon work supported by the U.S. National Science Foundation under grant CHE-1507975 and the Intramural Research Program of the National Institutes of Health, National Cancer Institute, Center for Cancer Research. 


\section{REFERENCES}

(1). Sabharwal SS, and Schumacker PT (2014) Mitochondrial ROS in Cancer: Initiators, Amplifiers or an Achilles' Heelff Nat. Rev. Cancer 14, 709-721. [PubMed: 25342630]

(2). Pani G, Giannoni E, Galeotti T, and Chiarugi P (2009) Redox-based Escape Mechanism from Death: The Cancer Lesson. Antioxid Redox Signaling 11, 2791-2806.

(3). Wilson WR, and Hay MP (2011) Targeting hypoxia in cancer therapy. Nat. Rev. Cancer 11, 393410. [PubMed: 21606941]

(4). Madajewski B, Boatman MA, Chakrabarti G, Boothman DA, and Bey EA (2016) Depleting Tumor-NQO1 Potentiates Anoikis and Inhibits Growth of NSCLC. Mol. Cancer Res. 14, 14-25. [PubMed: 26553038]

(5). Dinkova-Kostova AT, and Talalay P (2010) NAD(P)-H:quinone acceptor oxidoreductase 1 (NQO1), a multifunctional antioxidant enzyme and exceptionally versatile cytoprotector. Arch. Biochem. Biophys. 501, 116-123. [PubMed: 20361926]

(6). Fitzsimmons SA, Workman P, Grever M, Paull K, Camalier R, and Lewis AD (1996) Reductase enzyme expression across the national cancer institute tumor cell line panel: Correlation with sensitivity to mitomycin C and E09. J. Natl. Cancer Inst. 88, 259-269. [PubMed: 8614004]

(7). Sartorelli AC (1988) Therapeutic Attack of Hypoxic Cells of Solid Tumors: Presidential Address. Cancer Res. 48, 775-778. [PubMed: 3123053]

(8). Pardee AB, Li Y, and Li CJ (2002) Cancer Therapy with $\beta$-Lapachone. Curr. Cancer Drug Targets 2, 227-242. [PubMed: 12188909]

(9). Pink JJ, Planchon SM, Tagliarino C, Varnes ME, Siegel D, and Boothman DA (2000) NAD(P)H:Quinone Oxidoreductase Activity Is the Principal Determinant of $\beta$-Lapachone Cytotoxicity. J. Biol. Chem. 275, 5416-5424. [PubMed: 10681517]

(10). Parkinson EI, and Hergenrother PJ (2015) Deoxynybo-quinones as NQO1-Activated Cancer Therapeutics. Acc. Chem. Res. 48, 2715-2723. [PubMed: 26444384]

(11). Zhang L, Duan D, Liu Y, Ge C, Cui X, Sun J, and Fang J (2014) Highly Selective Off-On Fluorescent Probe for Imaging Thioredoxin Reductase in Living Cells. J. Am. Chem. Soc. 136, 226-233. [PubMed: 24351040]

(12). Pallua JD, Schaefer G, Seifarth C, Becker M, Meding S, Rauser S, Walch A, Handler M, Netzer M, Popovscaia M, Osl M, Baumgartner C, Lindner H, Kremser L, Sarg B, Bartsch G, Huck CW, Bonn GK, and Klocker H (2013) MALDI-MS Tissue Imaging Identification of Biliverdin Reductase B Overexpression in Prostate Cancer. J. Proteomics 91, 500-514. [PubMed: 23954705]

(13). Halim M, Yee DJ, and Sames D (2008) Imaging Induction of Cytoprotective Enzymes in Intact Human Cells: Coumberone, a Metabolic Reporter for Human AKR1C Enzymes Reveals Activation by Panaxytriol, an Active Component of Red Ginseng. J. Am. Chem. Soc. 130, 14123-14128. [PubMed: 18826220]

(14). Hettiarachchi SU, Prasai B, and McCarley RL (2014) Detection and Cellular Imaging of Human Cancer Enzyme Using a Turn-On, Wavelength-Shiftable, Self-Immolative Profluorophore. J. Am. Chem. Soc. 136, 7575-7578. [PubMed: 24813575]

(15). Kobayashi H, Ogawa M, Alford R, Choyke PL, and Urano Y (2010) New Strategies for Fluorescent Probe Design in Medical Diagnostic Imaging. Chem. Rev. 110, 2620-2640. [PubMed: 20000749]

(16). Rao JH, Dragulescu-Andrasi A, and Yao HQ (2007) Fluorescence imaging in vivo: recent advances. Curr. Opin. Biotechnol. 18, 17-25. [PubMed: 17234399]

(17). Razgulin A, Ma N, and Rao J (2011) Strategies for in vivo imaging of enzyme activity: an overview and recent advances. Chem. Soc. Rev. 40, 4186-4216. [PubMed: 21552609]

(18). van Duijnhoven SMJ, Robillard MS, Langereis S, and Grüll H (2015) Bioresponsive probes for molecular imaging: concepts and in vivo applications. Contrast Media Mol. Imaging 10, 282308. [PubMed: 25873263]

(19). Guo T, Cui L, Shen JN, Zhu WP, Xu YF, and Qian XH (2013) A highly sensitive longwavelength fluorescence probe for nitroreductase and hypoxia: selective detection and quantification. Chem. Commun. 49, 10820-10822. 
(20). Li YH, Sun Y, Li JC, Su QQ, Yuan W, Dai Y, Han CM, Wang QH, Feng W, and Li FY (2015) Ultrasensitive Near-Infrared Fluorescence-Enhanced Probe for in Vivo Nitroreductase Imaging. J. Am. Chem. Soc. 137, 6407-6416. [PubMed: 25923361]

(21). Li Z, Li XH, Gao XH, Zhang YY, Shi W, and Ma HM (2013) Nitroreductase Detection and Hypoxic Tumor Cell Imaging by a Designed Sensitive and Selective Fluorescent Probe, 7-[(5Nitrofuran-2-yl)methoxy]-3H-phenoxazin-3-one. Anal. Chem. 85, 3926-3932. [PubMed: 23506563]

(22). Xu J, Sun SB, Li Q, Yue Y, Li YD, and Shao SJ (2015) A rapid response "Turn-On" fluorescent probe for nitroreductase detection and its application in hypoxic tumor cell imaging. Analyst 140, 574-581. [PubMed: 25422882]

(23). Xu KH, Wang F, Pan XH, Liu RP, Ma J, Kong FP, and Tang B (2013) High selectivity imaging of nitroreductase using a near-infrared fluorescence probe in hypoxic tumor. Chem. Commun. 49, 2554-2556.

(24). Best QA, Johnson AE, Prasai B, Rouillere A, and McCarley RL (2016) Environmentally Robust Rhodamine Reporters for Probe-based Cellular Detection of the Cancer-linked Oxidoreductase hNQO1. ACS Chem. Biol. 11, 231-240. [PubMed: 26555574]

(25). Prasai B, Silvers WC, and McCarley RL (2015) Oxidoreductase-Facilitated Visualization and Detection of Human Cancer Cells. Anal. Chem. 87, 6411-6418. [PubMed: 26005900]

(26). Silvers WC, Prasai B, Burk DH, Brown ML, and McCarley RL (2013) Profluorogenic Reductase Substrate for Rapid, Selective, and Sensitive Visualization and Detection of Human Cancer Cells that Overexpress NQO1. J. Am. Chem. Soc. 135, 309-314. [PubMed: 23198810]

(27). McMahon KM, Volpato M, Chi HY, Musiwaro P, Poterlowicz K, Peng Y, Scally AJ, Patterson LH, Phillips RM, and Sutton CW (2012) Characterization of Changes in the Proteome in Different Regions of 3D Multicell Tumor Spheroids. J. Proteome Res. 11, 2863-2875. [PubMed: 22416669]

(28). Cox MC, Reese LM, Bickford LR, and Verbridge SS (2015) Toward the Broad Adoption of 3D Tumor Models in the Cancer Drug Pipeline. ACS Biomater. Sci. Eng. 1, 877-894. [PubMed: 33429520]

(29). Friedrich J, Seidel C, Ebner R, and Kunz-Schughart LA (2009) Spheroid-based drug screen: considerations and practical approach. Nat. Protoc. 4, 309-324. [PubMed: 19214182]

(30). Vinci M, Gowan S, Boxall F, Patterson L, Zimmermann M, Court W, Lomas C, Mendiola M, Hardisson D, and Eccles SA (2012) Advances in establishment and analysis of three-dimensional tumor spheroid-based functional assays for target validation and drug evaluation. BMC Biol. 10, 29. [PubMed: 22439642]

(31). Vahrmeijer AL, Hutteman M, van der Vorst JR, van de Velde CJ, and Frangioni JV (2013) Imageguided cancer surgery using near-infrared fluorescence. Nat. Rev. Clin. Oncol. 10, 507-518. [PubMed: 23881033]

(32). Nguyen QT, and Tsien RY (2013) Fluorescence-guided Surgery with Live Molecular Navigation - A New Cutting Edge. Nat. Rev. Cancer 13, 653-662. [PubMed: 23924645]

(33). Keereweer S, Van Driel PBAA, Snoeks TJA, Kerrebijn JDF, Baatenburg de Jong RJ, Vahrmeijer AL, Sterenborg HJCM, and Löwik CWGM (2013) Optical Image-Guided Cancer Surgery: Challenges and Limitations. Clin. Cancer Res. 19, 3745-3754. [PubMed: 23674494]

(34). van Dam GM, Themelis G, Crane LMA, Harlaar NJ, Pleijhuis RG, Kelder W, Sarantopoulos A, de Jong JS, Arts HJG, van der Zee AGJ, Bart J, Low PS, and Ntziachristos V (2011) Intraoperative tumor-specific fluorescence imaging in ovarian cancer by folate receptor-[alpha] targeting: first in-human results. Nat. Med. 17, 1315-1319. [PubMed: 21926976]

(35). Kobayashi H, and Choyke PL (2011) Target-Cancer-Cell-Specific Activatable Fluorescence Imaging Probes: Rational Design and in Vivo Applications. Acc. Chem. Res. 44, 83-90. [PubMed: 21062101]

(36). Kansanen E, Kuosmanen SM, Leinonen H, and Levonen A-L (2013) The Keap1-Nrf2 pathway: Mechanisms of activation and dysregulation in cancer. Redox Biol. 1, 45-49. [PubMed: 24024136] 
(37). Wang XJ, Sun Z, Villeneuve NF, Zhang S, Zhao F, Li Y, Chen W, Yi X, Zheng W, Wondrak GT, Wong PK, and Zhang DD (2008) Nrf2 enhances resistance of cancer cells to chemotherapeutic drugs, the dark side of Nrf2. Carcinogenesis 29, 1235-1243. [PubMed: 18413364]

(38). Zhang DD (2010) The Nrf2-Keap1-ARE Signaling Pathway: The Regulation and Dual Function of Nrf2 in Cancer. Antioxid. Redox Signaling 13, 1623-1626.

(39). Siegel D, Yan C, and Ross D (2012) NAD(P)H:quinone oxidoreductase 1 (NQO1) in the sensitivity and resistance to antitumor quinones. Biochem. Pharmacol. 83, 1033-1040. [PubMed: 22209713]

(40). O’Dwyer PJ, Perez RP, Yao K-S, Godwin AK, and Hamilton TC (1996) Increased DT-diaphorase expression and cross-resistance to mitomycin $\mathrm{C}$ in a series of cisplatin-resistant human ovarian cancer cell lines. Biochem. Pharmacol. 52, 21-27. [PubMed: 8678904]

(41). O’Dwyer PJ, Yao K-S, Ford P, Godwin AK, and Clayton M (1994) Effects of Hypoxia on Detoxicating Enzyme Activity and Expression in HT29 Colon Adenocarcinoma Cells. Cancer Res. 54, 3082-3087. [PubMed: 8205521]

(42). Ji L, Li H, Gao P, Shang G, Zhang DD, Zhang N, and Jiang T (2013) Nrf2 Pathway Regulates Multidrug-Resistance-Associated Protein 1 in Small Cell Lung Cancer. PLoS One 8, e63404. [PubMed: 23667609]

(43). Ahn KS, Sethi G, Jain AK, Jaiswal AK, and Aggarwal BB (2006) Genetic Deletion of $\mathrm{NAD}(\mathrm{P}) \mathrm{H}$ :Quinone Oxidoreductase 1 Abrogates Activation of Nuclear Factor- $\kappa \mathrm{B}, \mathrm{I} \kappa \mathrm{B} a$ Kinase, c-Jun Nterminal Kinase, Akt, p38, and p44/42 Mitogen-activated Protein Kinases and Potentiates Apoptosis. J. Biol. Chem. 281, 19798-19808. [PubMed: 16682409]

(44). Cui X, Li L, Yan G, Meng K, Lin Z, Nan Y, Jin G, and Li C (2015) High Expression of NQO1 is Associated with Poor Prognosis in Serous Ovarian Carcinoma. BMC Cancer 15, 244. [PubMed: 25885439]

(45). Ma Y, Kong J, Yan G, Ren X, Jin D, Jin T, Lin L, and Lin Z (2014) NQO1 overexpression is associated with poor prognosis in squamous cell carcinoma of the uterine cervix. BMC Cancer 14, 1-9. [PubMed: 24383403]

(46). Yang Y, Zhang Y, Wu Q, Cui X, Lin Z, Liu S, and Chen L (2014) Clinical implications of high NQO1 expression in breast cancers. J. Exp. Clin. Cancer Res. 33, 14. [PubMed: 24499631]

(47). Li Z, Zhang Y, Jin T, Men J, Lin Z, Qi P, Piao Y, and Yan G (2015) NQO1 protein expression predicts poor prognosis of non-small cell lung cancers. BMC Cancer 15, 1-9. [PubMed: 25971837]

(48). Peng L, Duan Y, Zhang Y, Zhao D, Wen Y, Yao J, and Da M (2016) Expression of Nrf2 and NQO1 in Human Gastric Cancer and Their Clinical Significance. Int. J. Clin. Exp. Pathol. 9, 1635-1643.

(49). Silvers WC, Payne AS, and McCarley RL (2011) Shedding light by cancer redox-human $\mathrm{NAD}(\mathrm{P}) \mathrm{H}$ :quinone oxidoreductase 1 activation of a cloaked fluorescent dye. Chem. Commun. 47, 11264-11266.

(50). Li LS, Bey EA, Dong Y, Meng J, Patra B, Yan J, Xie XJ, Brekken RA, Barnett CC, Bornmann WG, Gao J, and Boothman DA (2011) Modulating endogenous NQO1 levels identifies key regulatory mechanisms of action of beta-lapachone for pancreatic cancer therapy. Clin. Cancer Res. 17, 275-285. [PubMed: 21224367]

(51). Peng X, Song F, Lu E, Wang Y, Zhou W, Fan J, and Gao Y (2005) Heptamethine Cyanine Dyes with a Large Stokes Shift and Strong Fluorescence: A Paradigm for Excited-State Intramolecular Charge Transfer. J. Am. Chem. Soc. 127, 4170-4171. [PubMed: 15783189]

(52). Strekowski L, Lipowska M, and Patonay G (1992) Substitution-Reactions of a Nucleofugal Group in Heptamethine Cyanine Dyes - Synthesis of an Isothiocyanato Derivative for Labeling of Proteins with a near-Infrared Chromophore. J. Org. Chem. 57, 4578-4580.

(53). Descalzo AB, and Rurack K (2009) On the Signalling Pathways and CuII-Mediated Anion Indication of N-meso-Substituted Heptamethine Cyanine Dyes. Chem. - Eur. J. 15, 3173-3185. [PubMed: 19197932]

(54). Kiyose K, Aizawa S, Sasaki E, Kojima H, Hanaoka K, Terai T, Urano Y, and Nagano T (2009) Molecular Design Strategies for Near-Infrared Ratiometric Fluorescent Probes Based on the 
Unique Spectral Properties of Aminocyanines. Chem. - Eur. J. 15, 9191-9200. [PubMed: 19650089]

(55). Liu PL, Xu JS, Yan DH, Zhang PS, Zeng F, Li BW, and Wu SZ (2015) A DT-diaphorase responsive theranostic prodrug for diagnosis, drug release monitoring and therapy. Chem. Commun. 51, 9567-9570.

(56). Amsberry KL, and Borchardt RT (1990) The Lactonization of 2'-Hydroxyhydrocinnamic AcidAmides - a Potential Prodrug for Amines. J. Org. Chem. 55, 5867-5877.

(57). Levine MN, and Raines RT (2012) Trimethyl lock: a trigger for molecular release in chemistry, biology, and pharmacology. Chem. Sci. 3, 2412-2420. [PubMed: 23181187]

(58). Shin WS, Han J, Verwilst P, Kumar R, Kim JH, and Kim JS (2016) Cancer Targeted Enzymatic Theranostic Prodrug: Precise Diagnosis and Chemotherapy. Bioconjugate Chem. 27, 1419-1426.

(59). Sung YM, Gayam SR, Hsieh PY, Hsu HY, Diau EWG, and Wu SP (2015) Quinone-Modified Mn-Doped ZnS Quantum Dots for Room-Temperature Phosphorescence Sensing of Human Cancer Cells That Overexpress NQO1. ACS Appl. Mater. Interfaces 7, 25961-25969. [PubMed: 26540617]

(60). Gayam SR, Venkatesan P, Sung YM, Sung SY, Hu SH, Hsu HY, and Wu SP (2016) An $\mathrm{NAD}(\mathrm{P}) \mathrm{H}$ :quinone oxidoreductase 1 (NQO1) enzyme responsive nanocarrier based on mesoporous silica nanoparticles for tumor targeted drug delivery in vitro and in vivo. Nanoscale 8, 12307-12317. [PubMed: 27271875]

(61). Ong W, Yang YM, Cruciano AC, and McCarley RL (2008) Redox-Triggered Contents Release from Liposomes. J. Am. Chem. Soc. 130, 14739-14744. [PubMed: 18841890]

(62). Mendoza MF, Hollabaugh NM, Hettiarachchi SU, and McCarley RL (2012) Human NAD(P)H:Quinone Oxidoreductase Type I (hNQO1) Activation of Quinone Propionic Acid Trigger Groups. Biochemistry 51, 8014-8026. [PubMed: 22989153]

(63). Soper SA, and Mattingly QL (1994) Steady-State and Picosecond Laser Fluorescence Studies of Nonradiative Pathways in Tricarbocyanine Dyes - Implications to the Design of near-Ir Fluorochromes with High Fluorescence Efficiencies. J. Am. Chem. Soc. 116, 3744-3752.

(64). Rurack K, and Spieles M (2011) Fluorescence Quantum Yields of a Series of Red and NearInfrared Dyes Emitting at 600-1000 nm. Anal. Chem. 83, 1232-1242. [PubMed: 21250654]

(65). Kössler S, Nofziger C, Jakab M, Dossena S, and Paulmichl M (2012) Curcumin affects cell survival and cell volume regulation in human renal and intestinal cells. Toxicology 292, 123-135. [PubMed: 22178266]

(66). Benson AM, Hunkeler MJ, and Talalay P (1980) Increase of NAD(P)H:quinone reductase by dietary antioxidants: possible role in protection against carcinogenesis and toxicity. Proc. Natl. Acad. Sci. U. S. A. 77, 5216-5220. [PubMed: 6933553]

(67). Nawimanage RR, Prasai B, Hettiarachchi SU, and McCarley RL (2014) Rapid, Photoinduced Electron Transfer-Modulated, Turn-on Fluorescent Probe for Detection and Cellular Imaging of Biologically Significant Thiols. Anal. Chem. 86, 12266-12271. [PubMed: 25343216]

(68). Knox RJ, Jenkins TC, Hobbs SM, Chen S, Melton RG, and Burke PJ (2000) Bioactivation of 5(aziridin-1-yl)-2,4-dinitrobenzamide (CB 1954) by human NAD(P)H quinone oxidoreductase 2: a novel co-substrate-mediated antitumor prodrug therapy. Cancer Res. 60, 4179-4186. [PubMed: 10945627]

(69). Saunders MP, Patterson AV, Chinje EC, Harris AL, and Stratford IJ (2000) NADPH:cytochrome c (P450) Reductase Activates Tirapazamine (SR4233) to Restore Hypoxic and Oxic Cytotoxicity in an Aerobic Resistant Derivative of the A549 Lung Cancer Cell Line. Br. J. Cancer 82, 651-656. [PubMed: 10682679]

(70). Cummings J, Spanswick VJ, Gardiner J, Ritchie A, and Smyth JF (1998) Pharmacological and biochemical determinants of the antitumour activity of the indoloquinone EO9. Biochem. Pharmacol. 55, 253-260. [PubMed: 9484790]

(71). Smitskamp-Wilms E, Peters GJ, Pinedo HM, van Ark-Otte J, and Giaccone G (1994) Chemosensitivity to the indoloquinone EO9 is correlated with DT-diaphorase activity and its gene expression. Biochem. Pharmacol. 47, 1325-1332. [PubMed: 7514407]

(72). Beall HD, Murphy AM, Siegel D, Hargreaves RH, Butler J, and Ross D (1995) Nicotinamide adenine dinucleotide (phosphate): quinone oxidoreductase (DT-diaphorase) as a target for 
bioreductive antitumor quinones: quinone cytotoxicity and selectivity in human lung and breast cancer cell lines. Mol. Pharmacol. 48, 499-504. [PubMed: 7565631]

(73). Imai S, Kiyozuka Y, Maeda H, Noda T, and Hosick HL (1990) Establishment and Characterization of a Human Ovarian Serous Cystadenocarcinoma Cell Line that Produces the Tumor Markers CA-125 and Tissue Polypeptide Antigen. Oncology 47, 177-184. [PubMed: 2314830]

(74). Viswanadhan VN, Ghose AK, Revankar GR, and Robins RK (1989) Atomic physicochemical parameters for three dimensional structure directed quantitative structure-activity relationships. 4. Additional parameters for hydrophobic and dispersive interactions and their application for an automated superposition of certain naturally occurring nucleoside antibiotics. J. Chem. Inf. Model. 29, 163-172.

(75). Choyke PL, and Kobayashi H (2012) Medical Uses of Fluorescence Imaging: Bringing Disease to Light. IEEE J. Sel. Top. Quantum Electron. 18, 1140-1146.

(76). Dunn KW, Kamocka MM, and McDonald JH (2011) A Practical Guide to Evaluating Colocalization in Biological Microscopy. Am. J. Physiol. Cell Physiol 300, C723-742. [PubMed: 21209361]

(77). Luo S, Tan X, Fang S, Wang Y, Liu T, Wang X, Yuan Y, Sun H, Qi Q, and Shi C (2016) Mitochondria-Targeted Small-Molecule Fluorophores for Dual Modal Cancer Phototherapy. Adv. Funct. Mater. 26, 2826-2835.

(78). Lim SY, Hong KH, Kim DI, Kwon H, and Kim HJ (2014) Tunable heptamethine-azo dye conjugate as an NIR fluorescent probe for the selective detection of mitochondrial glutathione over cysteine and homocysteine. J. Am. Chem. Soc. 136, 7018-7025. [PubMed: 24754635]

(79). Karlsson H, Fryknäs M, Larsson R, and Nygren P (2012) Loss of cancer drug activity in colon cancer HCT-116 cells during spheroid formation in a new 3-D spheroid cell culture system. Exp. Cell Res. 318, 1577-1585. [PubMed: 22487097]

(80). Shield K, Ackland ML, Ahmed N, and Rice GE (2009) Multicellular spheroids in ovarian cancer metastases: Biology and pathology. Gynecol. Oncol. 113, 143-148. [PubMed: 19135710]

(81). Sodek KL, Ringuette MJ, and Brown TJ (2009) Compact spheroid formation by ovarian cancer cells is associated with contractile behavior and an invasive phenotype. Int. J. Cancer 124, 20602070. [PubMed: 19132753]

(82). Burleson KM, Boente MP, Pambuccian SE, and Skubitz AP (2006) Disaggregation and invasion of ovarian carcinoma ascites spheroids. J. Transl. Med. 4, 6. [PubMed: 16433903]

(83). Sutherland RM, Sordat B, Bamat J, Gabbert H, Bourrat B, and Mueller-Klieser W (1986) Oxygenation and Differentiation in Multicellular Spheroids of Human Colon Carcinoma. Cancer Res. 46, 5320-5329. [PubMed: 3756881]

(84). Prasai B, and McCarley RL (2016) Abstract 3095: Fluorescent probe activation and hNQO1 activity in solid tumor mimics. Cancer Res. 76, 3095-3095.

(85). Winter WE, Maxwell GL, Tian C, Sundborg MJ, Rose GS, Rose PG, Rubin SC, Muggia F, and McGuire WP (2008) Tumor Residual After Surgical Cytoreduction in Prediction of Clinical Outcome in Stage IV Epithelial Ovarian Cancer: A Gynecologic Oncology Group Study. J. Clin. Oncol. 26, 83-89. [PubMed: 18025437]

(86). Urano Y, Sakabe M, Kosaka N, Ogawa M, Mitsunaga M, Asanuma D, Kamiya M, Young MR, Nagano T, Choyke PL, and Kobayashi H (2011) Rapid cancer detection by topically spraying a gamma-glutamyltranspeptidase-activated fluorescent probe. Sci. Transl. Med. 3, 110ra119.

(87). Segal E, Prestwood TR, van der Linden WA, Carmi Y, Bhattacharya N, Withana N, Verdoes M, Habtezion A, Engleman G. Edgar, and Bogyo M (2015) Detection of Intestinal Cancer by Local, Topical Application of a Quenched Fluorescence Probe for Cysteine Cathepsins. Chem. Biol. 22, 148-158. [PubMed: 25579207]

(88). von Burstin J, Eser S, Seidler B, Meining A, Bajbouj M, Mages J, Lang R, Kind AJ, Schnieke AE, Schmid RM, Schneider G, and Saur D (2008) Highly Sensitive Detection of Early-Stage Pancreatic Cancer by Multimodal Near-Infrared Molecular Imaging in Living Mice. Int. J. Cancer 123, 2138-2147. [PubMed: 18709639]

(89). Asanuma D, Sakabe M, Kamiya M, Yamamoto K, Hiratake J, Ogawa M, Kosaka N, Choyke PL, Nagano T, Kobayashi H, and Urano Y (2015) Sensitive $\beta$-galactosidase-targeting Fluorescence 
Probe for Visualizing Small Peritoneal Metastatic Tumours in vivo. Nat. Commun. 6, 6463. [PubMed: 25765713]

(90). Matsuzaki H, Kamiya M, Iwatate RJ, Asanuma D, Watanabe T, and Urano Y (2016) Novel Hexosaminidase-Targeting Fluorescence Probe for Visualizing Human Colorectal Cancer. Bioconjugate Chem. 27, 973-981.

(91). Hama Y, Urano Y, Koyama Y, Kamiya M, Bernardo M, Paik RS, Shin IS, Paik CH, Choyke PL, and Kobayashi H (2007) A Target Cell-Specific Activatable Fluorescence Probe for In vivo Molecular Imaging of Cancer Based on a Self-Quenched Avidin-Rhodamine Conjugate. Cancer Res. 67, 2791-2799. [PubMed: 17363601]

(92). Cresteil T, and Jaiswal AK (1991) High Levels of Expression of the NAD(P)H:Quinone Oxidoreductase (NQO1) Gene in Tumor Cells Compared to Normal Cells of the Same Origin. Biochem. Pharmacol. 42, 1021-1027. [PubMed: 1651729]

(93). Beyer RE, Segura-Aguilar JE, and Ernster L (1988) The Anticancer Enzyme DT Diaphorase is Induced Selectively in Liver During Ascites Hepatoma Growth. Anticancer Res. 8, 233-238. [PubMed: 3129984]

(94). Belinsky M, and Jaiswal AK (1993) NAD(P)H:Quinone oxidoreductase1 (DT-diaphorase) Expression in Normal and Tumor Tissues. Cancer Metastasis Rev. 12, 103-117. [PubMed: 8375015]

(95). Bello RI, Gömez-Díaz C, Navarro F, Alcaín FJ, and Villalba JM (2001) Expression of NAD(P)H:Quinone Oxidoreductase 1 in HeLa Cells: Role of Hydrogen Peroxide and Growth Phase. J. Biol. Chem. 276, 44379-44384. [PubMed: 11567026]

(96). Phillips RM, de la Cruz A, Traver RD, and Gibson NW (1994) Increased Activity and Expression of NAD(P)H:Quinone Acceptor Oxidoreductase in Confluent Cell Cultures and within Multicellular Spheroids. Cancer Res. 54, 3766-3771. [PubMed: 8033096]

(97). Urano Y, Asanuma D, Hama Y, Koyama Y, Barrett T, Kamiya M, Nagano T, Watanabe T, Hasegawa A, Choyke PL, and Kobayashi H (2009) Selective Molecular Imaging of Viable Cancer Cells with pH-activatable Fluorescence Probes. Nat. Med. 15, 104-109. [PubMed: 19029979]

(98). Choi HS, Gibbs SL, Lee JH, Kim SH, Ashitate Y, Liu F, Hyun H, Park G, Xie Y, Bae S, Henary M, and Frangioni JV (2013) Targeted zwitterionic near-infrared fluorophores for improved optical imaging. Nat. Biotechnol. 31, 148-153. [PubMed: 23292608] 


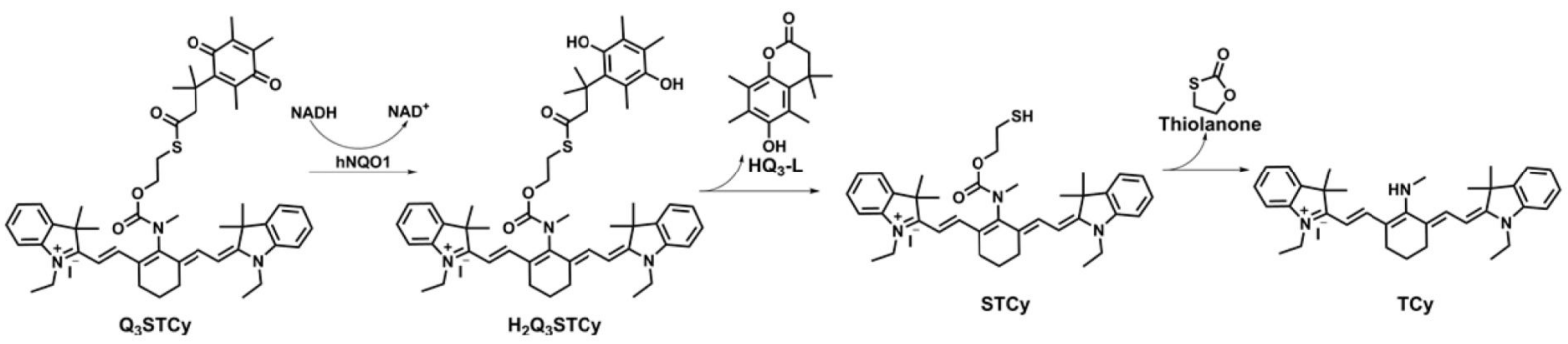

Scheme 1. Proposed TCy Reporter Release Path and Fluorescence Turn on by Treatment of Q33STCy with hNQO1 
A

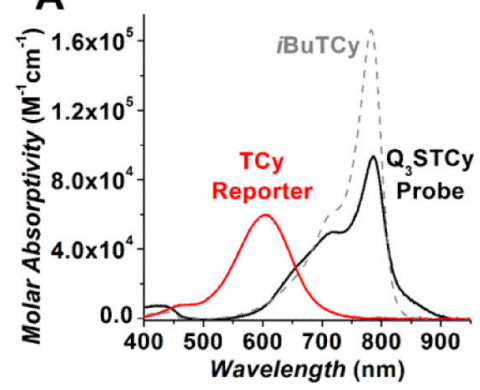

B

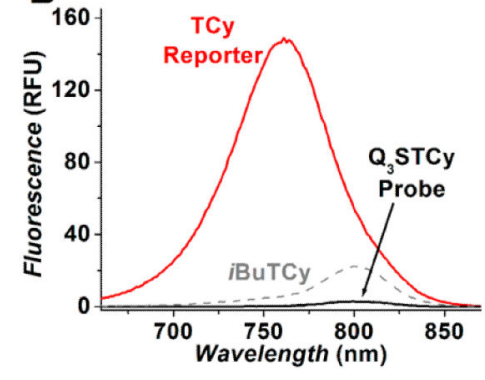

Figure 1.

Spectra of $2 \mu \mathrm{M}$ solutions in $1 \%$ DMSO/0.1 M PBS/0.1 M KCl solution ( $\mathrm{pH}=7.4)$. (A) Absorption and (B) emission spectra of TCy (red), $\mathrm{Q}_{3}$ TCy (black), and $i$ BuTCy (dashed). Emission spectra were measured with $\lambda_{\mathrm{ex}}=600 \mathrm{~nm} . T=25^{\circ} \mathrm{C}$. 

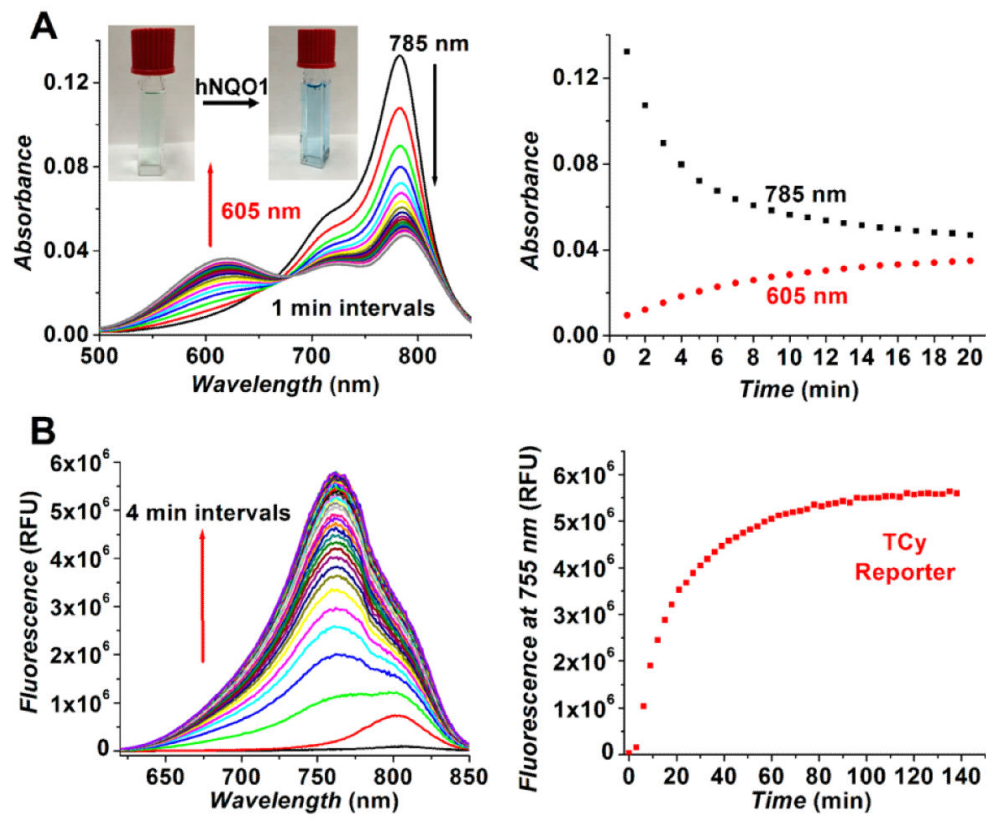

Figure 2.

Time-dependent spectral changes initiated by the addition of hNQO1 $\left(688 \mathrm{U} \mathrm{mL}^{-1}\right)$ with $100 \mu \mathrm{M}$ NADH cofactor in $0.1 \mathrm{M}$ PBS/0.1 M KCl solution $(\mathrm{pH}=7.4)$ containing $0.007 \%$ BSA $\left(U=1 \mathrm{nmol}\right.$ of cytochrome c reduced $\left.\min ^{-1}\right)$. (A) Absorption $\left(2 \mu \mathrm{M} \mathrm{Q}_{3}\right.$ STCy) spectra and corresponding change in absorbance maximum for the probe and reporter. (B) Emission (4 $\mu \mathrm{M} \mathrm{Q} \mathrm{Q}_{3} \mathrm{STCy}$ ) spectra and associated increase at the peak emission of the TCy reporter. Color changes are demonstrated by the inset in A. Absorption spectra were measured every $1 \mathrm{~min}$, and emission spectra were recorded every $4 \mathrm{~min} ; \lambda_{\mathrm{ex}}=605 \mathrm{~nm}$, excitation slit width $=5.0$, emission slit width $=7.5 . T=37^{\circ} \mathrm{C}$. 

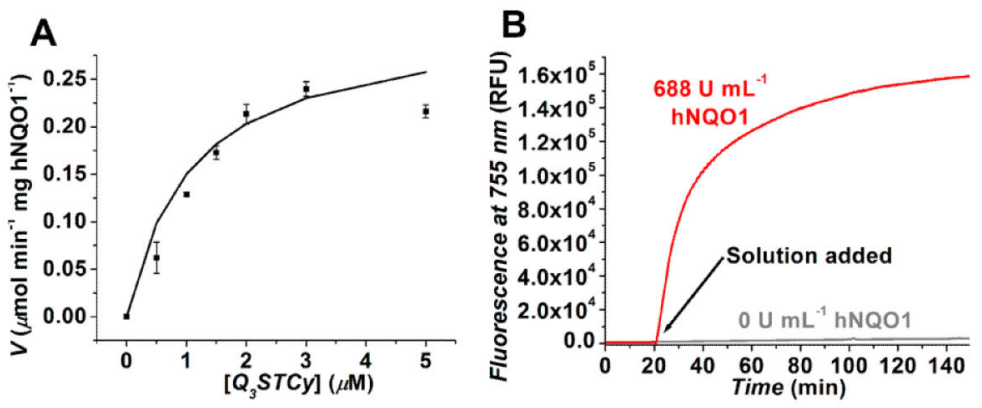

Figure 3.

(A) Kinetic plot of hNQO1 $\left(0.5 \times 10^{-6} \mathrm{~g} \mathrm{~mL}^{-1}, 250 \mathrm{U} \mathrm{mL}^{-1}\right)$ with $\mathrm{Q}_{3} \mathrm{STCy}$ as a substrate in $\mathrm{pH}$ 7.4, 0.1 M PBS solution containing 0.007\% BSA and $100 \mu \mathrm{M}$ NADH. Values shown are the average of three trials with errors bars being \pm 1 standard deviation; line is best fit to data ( $\left.\chi^{2}=0.00076\right)$. (B) The fluorescence $\left(\lambda_{\mathrm{ex}}=605 \mathrm{~nm}, \lambda_{\mathrm{em}}=755 \mathrm{~nm}\right)$ from a $4 \mu \mathrm{M}$ solution of $\mathrm{Q}_{3} \mathrm{STCy}$ was recorded with or without the addition of $688 \mathrm{U} \mathrm{mL}^{-1} \mathrm{hNQO} 1$ at the $20 \mathrm{~min}$ time point. $T=37^{\circ} \mathrm{C}$. 


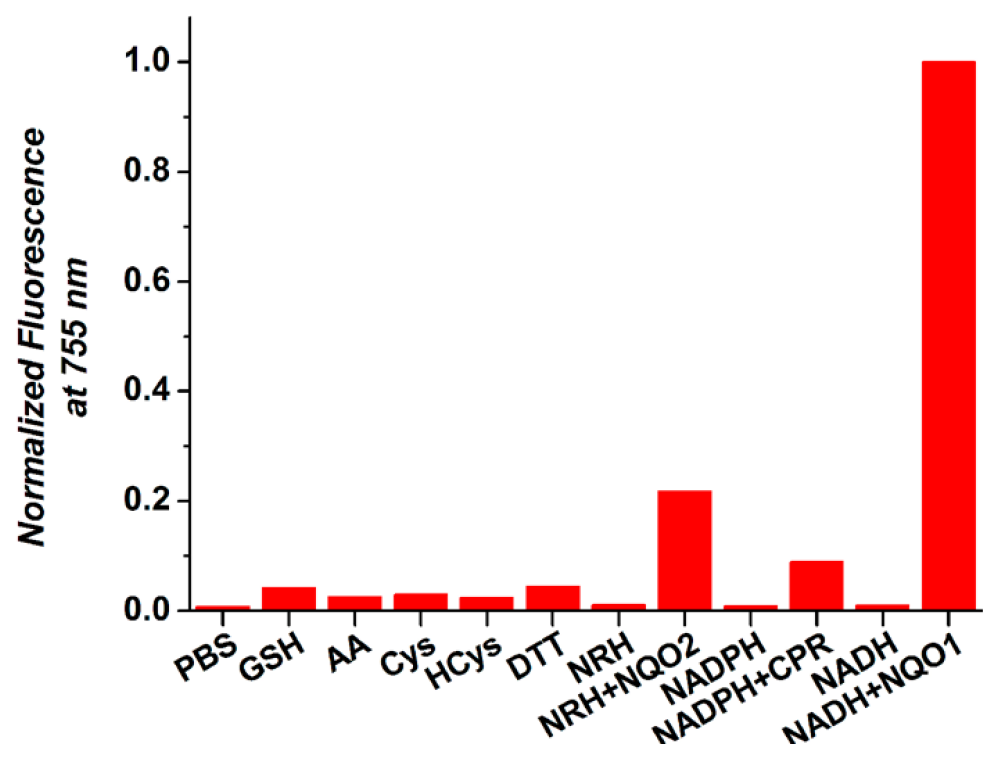

Figure 4.

Fluorescence $\left(\lambda_{\mathrm{em}}=755 \mathrm{~nm}, \lambda_{\mathrm{ex}}=600 \mathrm{~nm}\right)$ from solutions of $4 \mu \mathrm{M} \mathrm{Q} \mathrm{Q}_{3} \mathrm{STCy}$ after $20 \mathrm{~min}$ of incubation at $37{ }^{\circ} \mathrm{C}$ with various reducing agents and reductase enzymes in $\mathrm{pH}$ 7.4, 0.1 M PBS. Reducing agent concentrations: $1 \mathrm{mM}$ for ascorbic acid (AA) and thiols, $100 \mu \mathrm{M}$ for NRH cofactor of NRH:quinone oxidoreductase 2 (NQO2), and $100 \mu \mathrm{M}$ for NADH and NADPH. The reductases were present at $688 \mathrm{U} \mathrm{mL}^{-1}$ for hNQO1, $617 \mathrm{U} \mathrm{mL}^{-1}$ for NQO2, and $14.1 \mathrm{U} \mathrm{mL}^{-1}$ for cytochrome $\mathrm{P} 450$ reductase (CPR). 


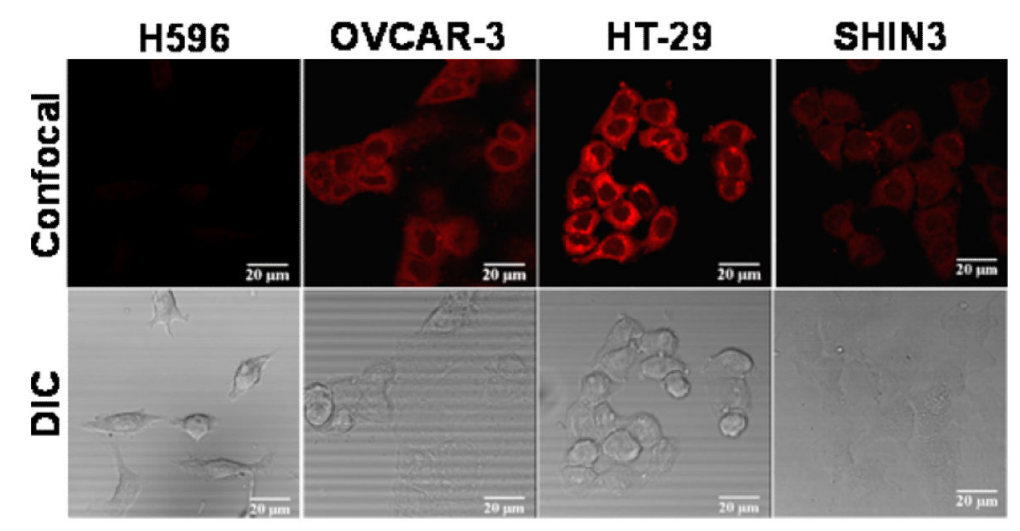

Figure 5.

Confocal and differential interference contrast (DIC) images of 24-h-old H596 (negative), OVCAR-3 (positive), HT-29 (positive), and SHIN3 (positive) cells incubated with $5 \mu \mathrm{M}$ $\mathrm{Q}_{3} \mathrm{STCy}$ for $30 \mathrm{~min}$ at $37{ }^{\circ} \mathrm{C}$. Fluorescence images were obtained using $633 \mathrm{~nm}$ excitation and 660-820 nm emission. A 1.0 Airy pinhole was used. Scale bar represents $20 \mu \mathrm{m}$. 


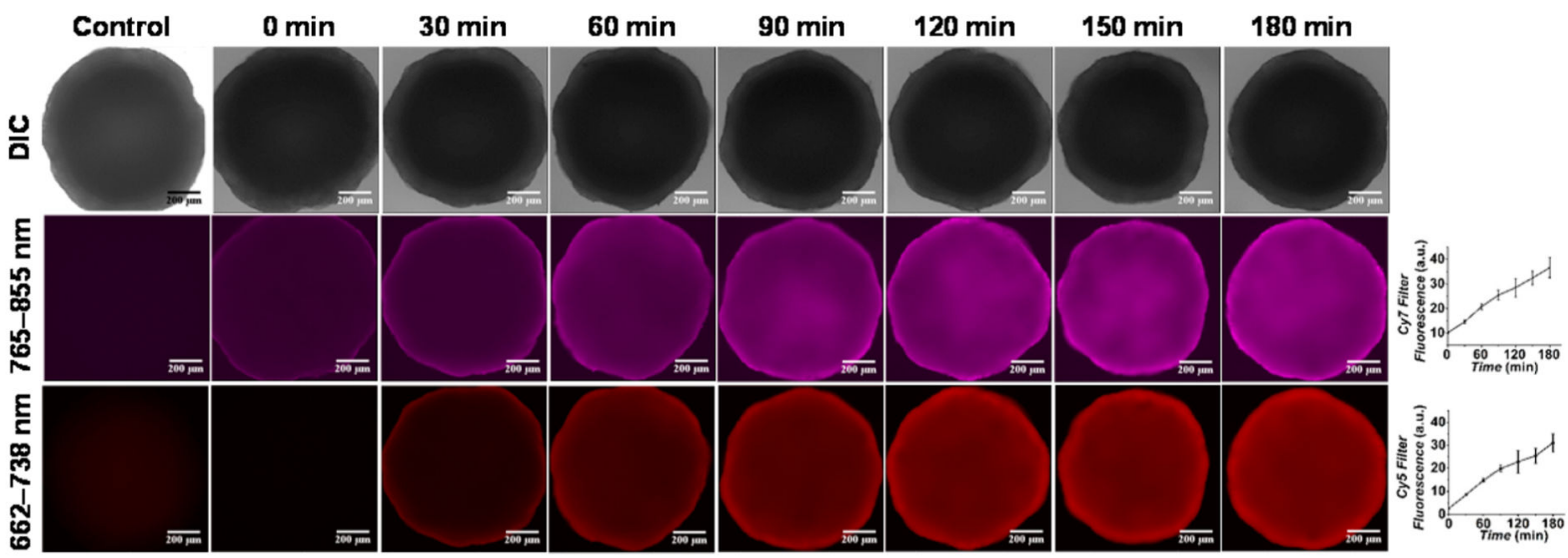

Figure 6.

Representative wide-field micrographs of living HT-29 colorectal cancer multicellular tumor spheroids (23 days old, $970 \pm 24 \mu \mathrm{m}$ diameter) in RPMI-1640 medium that were exposed to $5 \mu \mathrm{M} \mathrm{Q} \mathrm{Q}_{3} \mathrm{STCy}$ at $37^{\circ} \mathrm{C}$ for different times. Images were captured every $30 \mathrm{~min}$ using a Leica DM6 microscope with Cy7 ( $\lambda_{\mathrm{ex}}=672-748 \mathrm{~nm}, \lambda_{\mathrm{em}}=765-855 \mathrm{~nm} ; 50 \mathrm{~ms}$ exposure time) and Cy5 ( $\lambda_{\mathrm{ex}}=590-650 \mathrm{~nm}, \lambda_{\mathrm{em}}=662-738 \mathrm{~nm} ; 500 \mathrm{~ms}$ exposure time) filters. Note the necrotic core (dark center) in the differential interference contrast (DIC) images. Scale bar represents $200 \mu \mathrm{m}$. The control is a spheroid in medium without added probe. Reported fluorescence values are the average of measurements from four different spheroids, with error bars of \pm 1 standard deviation. 


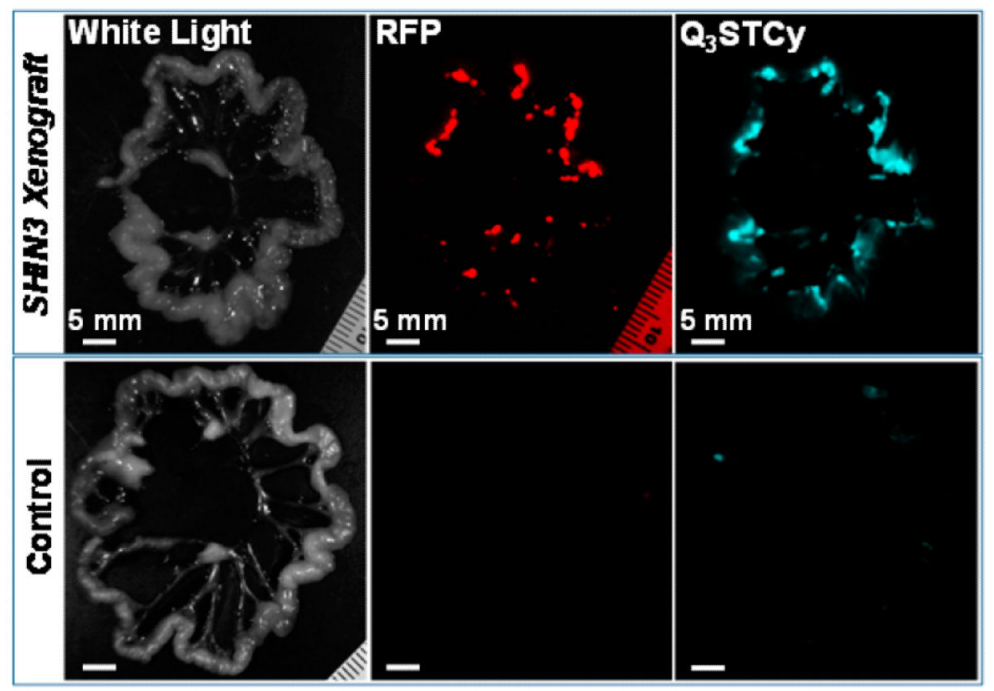

Figure 7.

Visualization of peritoneal metastases in SHIN3 mouse model of human ovarian cancer via fluorescence spectral imaging of mesentery at $1 \mathrm{~h}$ post intraperitoneal administration of $\mathrm{Q}_{3} \mathrm{STCy}$ (300 $\mu \mathrm{L}$ of $100 \mu \mathrm{M}$ probe in $\mathrm{pH}$ 7.4 PBS). Red fluorescent protein (RFP) signal results from the RFP-transfected cells (SHIN3-DsRed). Control designates mouse having no xenograft and treated with $\mathrm{Q}_{3} \mathrm{STCy}$. Scale bar represents $5 \mathrm{~mm}$. 